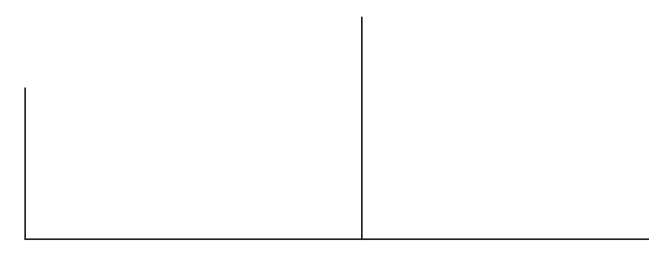

\title{
Considerações sobre o lugar do corpo na organização perversa
}

\author{
Edilene Freire de Queiroz
}

\begin{abstract}
Este artigo inicia fazendo algumas reflexões sobre o sentido de corpo para a psicanálise, partindo do princípio de que ele é distinto do da Biologia. Traz para o foco da discussão, o homem como ser de linguagem e analisa a forma de inscrição das experiências no aparelho psíquico. Situa a problemática do perverso na imagem que ele guarda da castração do corpo do Outro. Por fim, apresenta as contribuições trazidas por Rey-Flaud quanto aos níveis de perversão, de acordo com a maneira do perverso lidar com o objeto.
\end{abstract}




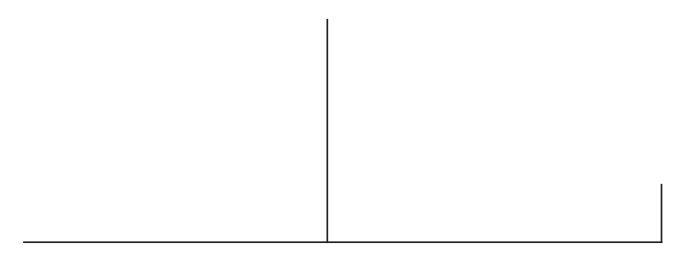

O fato da psicanálise fazer da linguagem o seu campo de ação e o instrumento privilegiado de sua eficácia, tem levado os seus críticos a exacerbarem a imagem de que ela negligencia o corpo, privilegiando a linguagem verbal, o discurso. Esta crítica torna-se mais incisiva para aqueles que vêem o corpo apenas como uma unidade biológica, e que, assim procedendo, acreditam que corpo e linguagem fazem parte de campos distintos. É comum se estabelecer uma oposição entre mente e corpo e de reconhecer que o segundo faz parte de um mundo exterior ao primeiro, mas necessário à constituição daquele. Este dualismo, marcante na tradição filosófica, tem favorecido a crença de que o interesse por um, implica, necessariamente, o esquecimento do outro. Além do que, a perspectiva com que cada corrente de pensamento "viesa" a noção de corpo, determina aproximações e distanciamentos entre estes dois pólos.

A noção de corpo em psicanálise, mais do que corpo matéria, está relacionada à noção de corpo energia. Um dos conceitos fundamentais da metapsicologia freudiana é o de pulsão, conceito-limite entre o somático e o psíquico, conceito que faz do corpo o elemento constitutivo de todas as elaborações psíquicas, à medida que este torna-se fonte de toda pulsão.

A descoberta de Freud de que todo o Ser do sujeito pode se fazer representar pela palavra, permitiu a ele criar um método de tratamento que, no seu nascedouro, recebeu o nome de "cura através da palavra", mas não arrefeceu nele o interesse em manter a vida psíquica articulada com a vida funcional do organismo.

Estudando as afasias, por exemplo, ele pôde constatar que havia uma impossibilidade de estabelecer uma explicação 


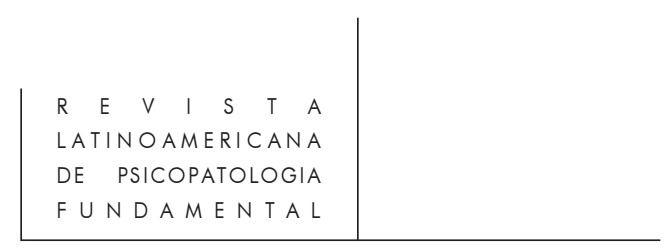

das alterações psíquicas fundada exclusivamente na hipótese de localização cerebral, afirmando que o organismo tendia a reagir como um todo e, portanto, apresentando uma perturbação funcional. Logo cedo pôde perceber que não havia uma equivalência entre funções mentais e órgãos ou zonas cerebrais. Mas o fato de não conceber o aparelho psíquico com uma localização específica no corpo, não quer dizer que ele prescinda deste; pode querer dizer, simplesmente, que para a psicanálise o corpo adquire um estatuto diferente do das ciências biológicas.

Nesta perspectiva o inconsciente pode ser concebido como podendo deslizar para qualquer parte do corpo, da mesma forma que qualquer parte do corpo pode se constituir em zona erógena. ${ }^{1}$ Freud, apesar de concebê-lo a partir de uma linguagem biologizante, ao longo de sua obra dá mostras de que a sua concepção de corpo parte do pressuposto de que o homem é um ser de linguagem e, como tal, qualquer leitura que se possa fazer do corpo estará atravessada por esta. O corpo representa uma primeira possibilidade do sujeito se constituir. Em "O ego e o id", Freud se refere a ele como a primeira maneira do ego ser.

De fato, para os psicanalistas, os acontecimentos empíricos e as experiências e sensações corporais não têm realidade, a não ser pelo discurso, pois só este confere a autenticidade da experiência. Isto coloca um problema no que se refere ao espaço-limite de atuação do psicanalista. A tendência tem sido a de circunscrever o campo da experiência psicanalítica a uma leitura dos processos psíquicos, sob o prisma das representações e dos significantes. Embora eles reconheçam que o corpo possa funcionar como imagem e depositário daquilo que não foi possível ser representado ao nível de palavra, reconhecem também que a psicanálise não dispõe de dispositivos próprios para lidar com tais questões.

Neste sentido, a psicanálise tem muito a agradecer aos psicanalistas que desenvolveram métodos para trabalhar com crianças, pois dada a peculiaridade de seus sujeitos tiveram que partir para uma escuta mais alargada dos processos psíquicos onde o corpo entrava como uma das linguagens possíveis. Igualmente destacamos as contribuições daqueles que se interessaram pela clínica da psicose e pela psicossomática. Lacan, por exemplo, ao falar de uma clínica do real, mostrou que existe algo que está no antes do inscrito no inconsciente, que faz eco na vida do sujeito e que se revela pela via do somático. A clínica psicanalítica tem mostrado que em algumas patologias, onde o recalque não se coloca como seu principal mecanismo, o corpo se impõe e marca uma presença que antecede a palavra. Um e outro caso têm exigido de nós um olhar mais atento para o corpo, encarando-o como um discurso possível de ser lido enquanto manifestação do

1. Lacan brinca com isto dizendo que o inconsciente pode estar no pé. Aliás, o pé é uma das partes do corpo preferida pelos perversos para se constituir como objeto fetiche. 


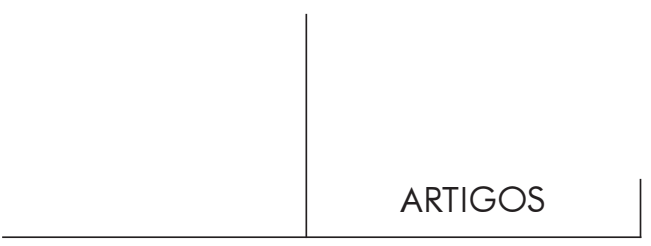

Ser. Não se trata de linguagem corporal ou linguagem dos gestos e comportamentos; trata-se de observar em que medida o corpo entra no discurso como mostração de algo que carece de significante.

\section{O corpo na teoria freudiana}

Remontando à construção do pensamento freudiano, podemos verificar que a questão de corpo e mente já estava posta desde os estudos sobre as afasias, mas foi, a partir dos estudos sobre a histeria que Freud deu início à construção de uma metapsicologia cujo conceito fundamental é o de pulsão. Pôs em xeque a noção de instinto, uma noção tão arraigada na biologia, e rompeu com a possibilidade de se pensar um corpo humano puramente biológico.

A primeira noção que ele construiu, justificando o aparecimento da histeria, foi a de trauma. De saída, pensou que o trauma se dava quando alguém vivia, no seu próprio corpo, uma experiência de transgressão. Posteriormente, pensou que o afeto, enquanto excedente, estava incontestavelmente relacionado com o mal e, portanto, precisando ser curado. Mas a noção de afeto não era suficiente para dar conta do bloqueio provocado pelo trauma e verificou que o que estaria em jogo era o fato de se experimentar algo, como diz Schneider (1993), no escuro, sem haver, concomitantemente, um significante que o representasse e o significasse. Assim, da noção de uma ferida no corpo, Freud passou a ver o traumatismo como uma experiência que se dava ao nível de uma supressão daqueles afetos que, uma vez vividos intensamente, impossibilitavam sua representação. Por conseguinte, tratava-se de um traumatismo psíquico que, segundo a mesma autora (p. 15), agia como se fosse um corpo estranho.

Avançando na compreensão dos fenômenos de conversão histérica, Freud pôde identificar dois elementos da pulsão - o afeto e a idéia ou o conteúdo ideativo - que se manifestavam em dois níveis diferentes. Um ao nível corporal, pelas manifestações do quantum afetivo, e outro ao nível mental. Um e outro nem sempre estavam ligados numa mesma representação pulsional, podendo seguir destinos diferentes. Mas o reconhecimento de uma experiência só se dava quando esses dois elementos se ligavam numa mesma representação de palavra. Em outros termos, quando o vivido era mediado pela palavra.

Esta idéia, de um corpo habitado pela linguagem, que vem desde Freud, se desdobra, hoje, em várias noções de corpo - corpo pulsional, corpo erógeno, corpo imaginário, corpo simbólico e corpo sujeito. Lacan prefere abordá-lo na perspectiva de três registros - na do real, na do imaginário e na do simbólico.

Na primeira, a do corpo enquanto real, ele é concebido como mais próximo da noção de organismo, funcionando como matéria-prima e fonte de energia. $\mathrm{Na}$ 


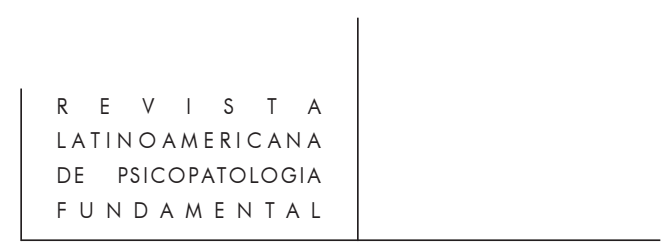

segunda, a do corpo imaginário, ele pode ser entendido como aquele que permite pensar o Ser enquanto constituído numa gestalt. E, por último, o corpo simbólico onde está implicado o sujeito falante, capaz de representar e converter para o corpo os seus pensamentos, as suas fantasias etc.

Estas três possibilidades de registro do corpo, de acordo com a ótica de Lacan, aparecem sempre enodadas servindo de unidade mínima para a constituição do sujeito. Há uma ordem simbólica que precede a existência do sujeito tornandose completamente inviável pensar o corpo puramente como biológico, além do que, quando pensamos estamos ao nível de representações mentais, e mesmo quando imaginamos ou representamos um corpo despedaçado, é de um corpo pulsional que se trata.

Há, portanto, uma descontinuidade entre o organismo e o corpo, que Joel Birman expressa muito bem quando se refere ao corpo da psicanálise como um corpo-sujeito, ou seja, um corpo marcado pelo Outro, pela linguagem. Diz ele:

Pode-se dizer de modo pontual, que o registro do corpo se refere a um remanejamento do registro do organismo pelos investimentos pulsionais e libidinais constituindo-se, então, em um outro território onde a ligação seria irredutível ao organismo. ("Le corps et l'affect en psychanalyse", Texto da Conferência proferida no Cercle Freudien, Paris, 08.11.95, p.12).

Contudo, dizer que um corpo é habitado pela linguagem não significa necessariamente dizer que a única via de acesso a ele seja a do significante e que todo o vivido possa se fazer representar pela palavra. As expressões artísticas dão mostras de outras possibilidades. Há um sentido vivido no corpo que nem sempre leva a uma significação, mas é sentido e faz registro no aparelho mental como, por exemplo, a dor.

Sobre isto o perverso tem muito a nos ensinar, pois ele impõe sofrimento ao corpo do Outro com o objetivo de fazer um atravessamento do prazer ao gozo saindo do registro do princípio do prazer para um para além, ou seja, saindo do registro de uma experiência de prazer parcial, marcada pela castração, para a busca da plenitude, de um prazer sem limites - para um para além do prazer e da representação.

A idéia de que existe alguma coisa que está para além da representação verbal, parece ficar evidente quando dirigimos nossa atenção para o mecanismo básico adotado pelo perverso - a Verleugnung - o desmentido. Esta noção pode ser entendida como algo que faz registro no aparelho mental, sem que necessariamente passe pelo dito. Há uma espécie de contradição intrínseca na própria significação da palavra alemã, entre o que se ouve e o que se vê, como se se ouvisse uma coisa e se visse outra. Na minha experiência clínica tem me chamado atenção a resistência de certos analisantes em deitar no divã, dizendo que não suportam 


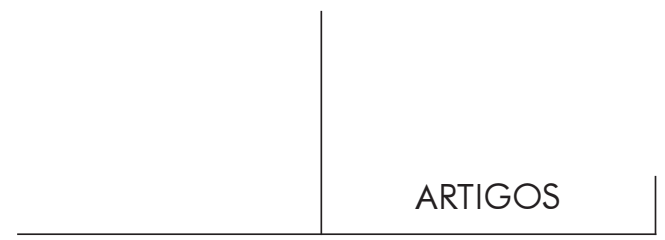

ficar sem serem vistos ou privados da visão. Para estes, não basta serem ouvidos; é preciso serem vistos e o corpo se impõe como uma presença nas sessões, muitas vezes, e antes mesmo, de uma fala. A escopofilia, como uma das manifestações da perversão polimorfa da infância, parece se manifestar neste espaço transferencial apontando para um momento da constituição da vida psíquica onde a pulsão escópica era fundamental. Lembro aqui Lacan que, ao falar do Estádio do Espelho, diz que o olhar tem uma função antecipatória na montagem de uma gestalt do corpo e, consequientemente, na constituição do ego. E lembro também de Jean Clavreul (1990) que, ao se referir ao perverso na relação analista-analisante, fala de uma certa relação de cumplicidade que se inicia pelo olhar - mostrar e ser visto. Estas observações nos levam a conjeturar o quanto o corpo está implicado nas análises de perversos.

Os estudos sobre as psicoses, sobre as perversões e sobre as doenças psicossomáticas têm revelado uma realidade de discurso que denuncia exatamente uma falha no mecanismo da representação, impedindo que o vivido possa ser representado por palavra. Gostaríamos, então, de abrir um parêntese nesta discussão, para fazer algumas considerações a respeito do processo de inscrição de qualquer material no aparelho mental. Elas nos ajudam a compreender, o que estamos situando como falha no mecanismo da representação.

Qualquer inscrição no aparelho mental se processa pelo menos em dois tempos: um tempo da Bejahung (afirmativo) que se faz acompanhar de um segundo, o da Verneinung (negativo). O primeiro como um substituto da união, como nos diz Hanns (1996, p. 50) e, portanto, pertencente a Eros, e o segundo, como sucessor da expulsão, relativo à destruição. Um e outro são discutidos por Freud no texto da "A negação", como elementos necessários para se reconhecer a existência de algo. Mas ao discutir sobre o juízo de atribuição, Freud coloca a função de julgar como uma continuidade do processo original por meio do qual o ego integra as coisas a si. Embora Freud tenha utilizado pouco o termo Bejahung, este parece se referir à primeira marca, à entrada de qualquer coisa no aparelho psíquico, através do sistema perceptivo, e que se faz acompanhar por um segundo momento caracterizado por três possibilidades de negação.

A primeira delas - a Verleugnung - normalmente traduzida por recusa ou desmentido, estaria ligada ao sistema perceptivo. Seu sentido está em negar a presença de algo cujo conteúdo é insuportável, e que funciona, como nos diz Kaufmann (1996, p. 447), como uma espécie de placa giratória entre neurose, psicose e perversão.

A segunda - a Verdrangung - recalque, repressão, estaria ligada ao sistema de representação e significaria negar colocando de lado, para evitar o confronto com a representação (Vorstellung). Esta parece ser uma segunda possibilidade de negação, o que supõe a existência de uma primeira, a Verleugnung, e que, 


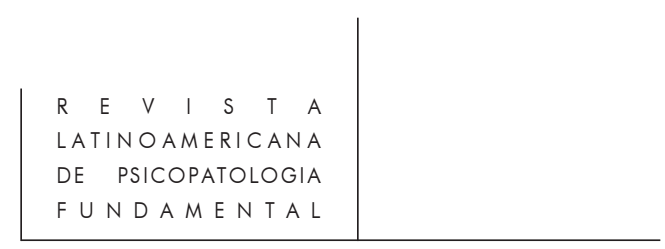

por sua vez, abre caminho para uma terceira, a Verneinung. Esta última estaria mais ao nível do julgamento, da passagem do material recalcado à consciência. Ela permite uma certa iniciação da tomada de consciência do recalcamento sem que o sujeito aceite o seu conteúdo (Freud, “A negação", 1985/1925), o que supõe que as duas anteriores já tenham ocorrido.

Há ainda um quarto sentido de negação, ligado ao termo Verwerfung, que significa rejeição e forclusão, e pode ser interpretado como uma negação mais drástica, posto que expulsa um conteúdo do campo da representação, como acontece nas psicoses. Segundo Kaufmann, quando se trata da psicose, a forclusão do Nome do pai aparece em paralelo com o desmentido.

Estas noções nos ajudam a pensar este tempo que antecede o recalque, ou seja, um momento anterior à constituição neurótica, permitindo considerar a perversão como uma organização que mostra mais claramente este momento entre o percebido e o representado. Diante destas alternativas de negativas colocadas por Freud, podemos interpretar a afirmativa de que "a neurose é o negativo da perversão", como a possibilidade de, na neurose, estar colocada uma negação dupla, se levarmos em conta que a inscrição da castração do Outro se dá em dois níveis: ao nível do sistema perceptivo, como já foi colocado acima - a Verleugnung, o desmentido - e ao nível da representação - a Verdrangung, o recalque.

Já no perverso, uma vez que o seu mecanismo básico é a Verleugnung, a negativa da castração fica ao nível da primeira, havendo um certo fracasso da segunda. A clínica tem nos revelado que a fantasia perversa no neurótico é o que há de mais escondido, diferente dos sintomas que o sujeito fala com muita facilidade. Questionamos se a negação dupla pela qual passam aqueles que se organizam num modo de subjetivação neurótica, não poderia ser responsável por isto. A fantasia coloca o sujeito frente ao seu desejo, posição repreensível para o neurótico que faz questão de esconder seu desejo a sete chaves. As fantasias perversas dos neuróticos são uma espécie de espetáculo privado, enquanto as dos perversos, além de facilmente serem atuadas, são colocadas no plano público, e mesmo quando elas são reveladas em lugares privados, como no espaço da análise, o objetivo é fazer do Outro, que as escuta, um cúmplice, como bem observa Jean Clavreul. Neste sentido, a perversão pode ser vista como uma condição do Ser que antecede a instalação da constituição neurótica e divisora de águas no se refere aos destinos do percebido: ou recalca ou forclui ou permanece no desmentido. 


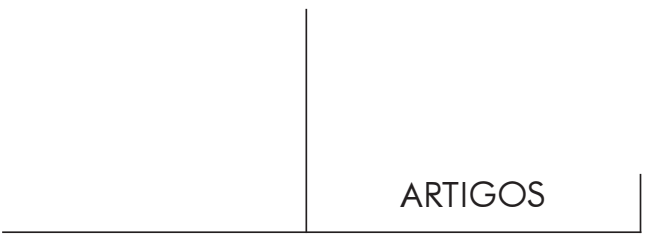

O corpo na organização perversa

Parece que os autores são unânimes em afirmar que a problemática do perverso se situa na imagem que ele guarda da castração do corpo do Outro, ao mesmo tempo que faz um desmentido da castração feminina. Ele tenta encobrir a falta da mulher com um véu, de modo a não ver/vendo, e tenta também, a todo custo, restituir-lhe o que lhe falta. A fotografia de Sílvia Ribeiro, que ilustra a capa do livro de Maria Rita Kehl A mínima diferença, é bastante sugestiva deste sentido de ocultação/revelação, própria da problemática do perverso. Ela apresenta a imagem de um corpo de mulher, nu, mas encoberto, da cintura para baixo, por uma gaze. Da mesma forma, Sade (1995/1795) mostra, em um dos diálogos travados entre Dolmancé e Madame Saint-Ange, o quanto este estado de não ver/vendo é condição necessária para que, nesse entre e nessa ambigüidade, se instale o jogo da sedução, próprio da situação fundamental do amor. Diz Madame Saint-Ange: “...aqui estão estas túnicas de gaze que ocultarão somente aquilo que se deve esconder ao desejo”. (p. 46)

Segundo Lacan (1995, p. 157), a presença do véu permite que aquilo que está mais além, como a falta, se realize como imagem, ou melhor, permite que se projete e se imagine a ausência. E como é possível ver a falta? Colocando no seu lugar um objeto imaginário, um objeto que se imagina que falta. A dimensão imaginária aparece como prevalente na organização perversa. Ou ele se imagina como este objeto que falta à mãe, desatarrachado dela, ou ele imagina e investe num objeto substitutivo que preencha esta falta. No primeiro caso mantém-se identificado ao objeto que falta à mulher submetendo-se como escravo aos caprichos dela. No segundo, cria um objeto substitutivo fazendo deste o seu fetiche. Numa e noutra situação é sempre de um objeto parcial que se trata.

Esta questão faz com que a relação do perverso com o Outro seja problemática. Ele se coloca como objeto do gozo do Outro ao mesmo tempo em que goza do corpo deste, enquanto corpo/partes. Ele sabe que não pode gozar do corpo completo e por isto o reparte. A obra de Sade é rica em descrições de cenas que revelam o desejo do carrasco sadiano em fragmentar o corpo do Outro, destituindo-o de toda e qualquer unidade e completude, ao mesmo tempo em que provoca, na sua vítima, uma divisão subjetiva do eu, levando-a a viver as agruras de uma dor transmutada em gozo, em gozo mortífero e mortal. Há uma espécie de atravessamento da pulsão de vida, pela pulsão de morte, cujo princípio, nós sabemos tão bem qual é - o de quebrar a unidade. Ao agir assim, o perverso faz do Outro um objeto do seu gozo, não reconhecendo nele um sujeito. O neurótico tem um saber não sabido sobre a falta, mas mantém a ilusão de que pode se completar com o Outro, e por isto sofre, porque o seu encontro com o Outro é sempre faltoso. O amor vem então preencher este hiato e apaziguar este 


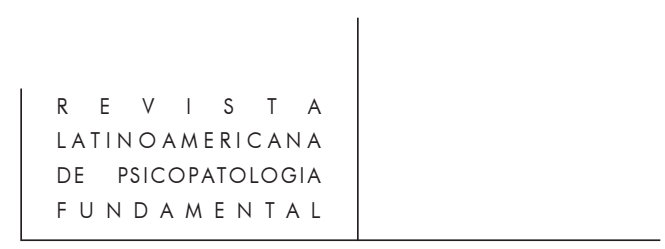

sofrimento. Já o perverso não tem um saber sobre a falta, uma vez que não a reconhece. Este saber se encontra tamponado pelo desmentido e, portanto, ele não aspira se completar com o Outro.

Se na vida todos nós temos o direito de gozar do corpo do Outro, este direito passa pelo consentimento deste Outro. O Outro é visto também como um sujeito de desejo e é isto que impõe limite ao nosso gozo. Assim, temos a consciência de que se trata de uma posse relativa; afinal, o máximo que podemos fazer com o corpo do Outro, é uma atividade de apreensão, tais como tocá-lo, penetrá-lo, etc., como nos diz Jacques-Alain Miller referindo-se a Lacan (1997, p. 183). Ao contrário, o perverso goza do corpo do Outro sem pedir-lhe permissão, uma vez que o Outro está colocado ali apenas como objeto do seu gozo, ou talvez fosse melhor dizer, como objetos do seu gozo, já que se trata de corpo fragmentado. O limite do seu capricho no uso do corpo do Outro é morrer ou matar.

Por outro lado, ele próprio também se faz objeto para o Outro, pois todos os seus atos são determinados por um imperativo categórico de dever gozar, determinados por uma lei, por uma voz imperiosa que vem do Outro, este Outro primordial que alguns autores, como Serge André (1995), associam ao pai primevo, ao pai da Horda. Diz esse autor (p. 49) que a forma como Freud coloca a figura do pai em "Totem e tabu", constitui um problema, posto que o modelo mítico do pai da horda revela um pai fundante de uma lei, mas que ao mesmo tempo detém o gozo pleno. Assim, de um lado ele proíbe gozar, mas de outro ele ordena gozar. O perverso se manteria identificado a este pai, como se ficasse preso à pré-história da lei. Sabemos que a função do pai da horda é gozar de todas as mulheres assegurando uma função de exceção, de Um, que o deixa livre da castração. A partir deste Um é que se funda o universal da lei. Contudo, ao ficar preso ao universal, ele não pode se colocar na regra, mas sim na exceção a ela. Esta hipótese levantada por Serge André permite pensar que, no caso da perversão, não há sujeitos e sim assujeitados, pois da mesma forma que suas vítimas, o perverso também se coloca como assujeitado à versão de uma lei, a do pai primevo, e não à versão de uma lei consensualmente aceita. ${ }^{2}$

Até aqui situamos a problemática do perverso na sua relação com o corpo, tendo como norte o seu mecanismo básico e a dificuldade que ele apresenta na sua relação com o Outro. Estas duas variáveis que distinguem o perverso das demais formas de organização subjetiva, podem ser tomadas como traços gerais que ajudam a contextualizar a perversão. Há, contudo, um outro modo de vê-la:

2. Lacan, associando a homofonia do termo perversion à pèrelversion, mostra que a problemática do perverso está revelada no próprio termo que o denomina. 


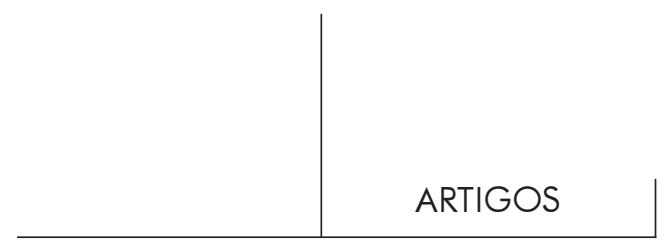

a partir da maneira com que o sujeito lida com o objeto e, neste sentido, podese identificar níveis de perversão. Esta é a visão de Henri Rey-Flaud, que apresentaremos em seguida, finalizando estas considerações sobre o lugar do corpo na organização perversa. Destacamos alguns aspectos relevantes do trabalho sobre o fetichismo empreendido por este autor (1994), fruto de quinze anos de estudos e análise da obra de Freud sobre o assunto. Ele nos revela que, na perversão, existe duas maneiras de se lidar com o objeto: ou se fica com o objeto bruto ou o eleva à categoria de das Ding tornando-o um objeto idealizado.

\section{O objeto-fetiche do perverso segundo Rey-Flaud}

O fetichismo tem sido sempre apontado como modelo de uma estrutura perversa. A sua gênese está determinada pela impossibilidade de reconhecer a falta na mulher, como já indicamos anteriormente.

Os primeiros estudos de Freud o levaram a identificar o objeto-fetiche como um objeto substituto simbólico do pênis que falta à mulher. Ele teria então como função recobrir realidades diferentes. Inicialmente se processava um deslocamento metonímico, fazendo com que a pessoa amada fosse substituída por uma parte do seu corpo e, num segundo tempo, este objeto-parte do corpo era idealizado, elevado à categoria de das Ding, tornando-se um objeto destacado do corpo.

Nestes primeiros estudos, toda esta noção de objeto-fetiche ainda estava agregada a uma forma particular de manifestação neurótica, regido por um modo singular de recalcamento - o recalcamento parcial - que foi introduzido como uma solução mediana, entre a conservação perversa da satisfação infantil e o recalcamento dessa satisfação. Assim, o fetichismo já seria um meio caminho em direção à neurose, ao passo que o perverso propriamente dito, ou seja, aquele que toma o objeto bruto, manteria sua satisfação sem recalcamento. A parte do objeto que sofresse o recalcamento seria então, idealizada, tornando-se objetofetiche. O que se observava era que um traço, um significante, se encontrava separado de seu contexto primitivo, ou de seu complexo representativo, fazendo com que o objeto fosse clivado e marcado por uma singular idealização.

A idealização é uma operação que seleciona um traço atributivo do objeto (ein einziger Zug) e eleva este traço à função de significar todos os significantes do objeto. Seria decorrente de um efeito metafórico. Esta idealização confere às relações amorosas um caráter compulsivo, explicando, assim, porque tais paixões se repetem várias vezes, com os mesmos traços e com as mesmas particularidades. Mantém-se aí uma natureza dupla do traço: de se inscrever, ao mesmo tempo, em dois registros diferentes. Um que se conserva na memória individual do sujeito, como marca do gozo primitivo. E outro que se inscreve 


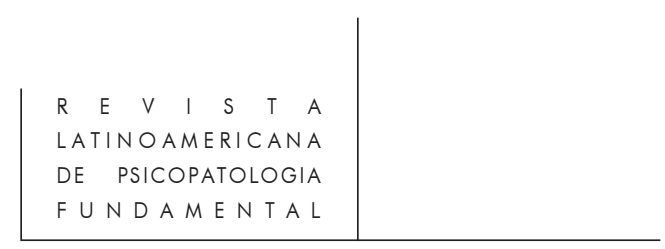

como objeto idealizado, dividido num sujeito e num Outro. É aí que reside a diferença fundamental entre a idealização presente nos casos de amor e a presente na organização fetichista, pois, neste último, há uma exclusão do Outro o que implica, conseqüentemente, numa exclusão do sistema representativo. Os apaixonados, ao idealizarem seus objetos de amor, falam deles, ao passo que, ao fetichista, está interdito falar, uma vez que para este último o fenômeno não se encontra no espaço significante.

Seguindo a construção feita por Ray-Flaud trata-se, no caso do fetichista, de um objeto decantado, destituído de qualquer atributo significante e elevado à pura substância, a objeto puro, a das Ding. Isto faz com que o perverso se instale em uma relação de puro gozo, como um assujeitado, enquanto o neurótico se mantém preso à lei do significante.

Contudo, mesmo o fetichismo sendo apontado como modelo de uma estrutura perversa, Rey-Flaud distingue-o como sendo um modo particular de perversão. Comenta o mesmo autor que no fetichismo já há uma elaboração do objeto, enquanto na perversão ele é colocado como objeto bruto.

... o fetichista "seleciona" um atributo da mulher (o pé sujo), que ele retém para representar (no sentido do alemão vertreten) o conjunto dos atributos perdidos do objeto, a fim de produzir, ao término da operação, um objeto "puro" que realizará a essência do objeto, ou seja, das Ding. (Tradução da autora) ${ }^{3}$

O fetichista estaria, assim, num momento lógico mais avançado que o perverso propriamente dito, uma vez que, por efeito de metáfora, consegue manter o paradoxo de conservar a ausência, presentificando-a num objeto, ou seja, manter a falta objetivando-a num objeto palpável, corporificável, substancializável.

Podemos, então, estabelecer uma certa gradação em direção a uma organização significante - a perversão propriamente dita, que toma o objeto no seu estado bruto, o fetichismo, onde já está implicado uma certa elaboração do objeto, e, a neurose, onde o objeto se faz representar. A constituição do objeto fetiche poderia ser comparado ao objeto transicional, pois em ambos os casos trata-se de falsas representações; o objeto transicional, ligado ao seio, e, o objetofetiche, ao pênis. E falo pênis em vez de falus porque ao nível da perversão os objetos adquirem substância.

Esta leitura minuciosa que Rey-Flaud faz da obra de Freud, no que se refere ao fetichismo, permite que avancemos no estudo da perversão. A compreensão

3. “... le fétichiste 'selectionne' un attribut de la femme (le pied sale), qu'il retient pour représenter (au sens de l'allemand vertreten) l'ensemble des attributs perdus de l'objet, afin de produire, au terme de l'opération, un objet 'pur' Qui réalisera l'essence de l'objet, c'est-àdire das Ding." (p. 75) 


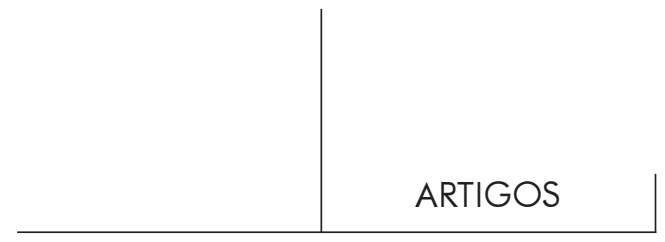

que se possa ter do lugar do corpo na organização perversa, com certeza, contribuirá na forma como a psicanálise irá se posicionar com relação às questões do corpo e, sobretudo, com relação ao estatuto deste no espaço da análise.

Diante do exposto, temos clareza de que a psicanálise não negligencia o corpo, mas reconhecemos que algumas questões carecem de melhores esclarecimentos. A dificuldade dos perversos de se manterem em análise, tão difundida na literatura psicanalítica, é uma delas. Sobre isto só temos dois caminhos a seguir: ou nos abrimos para ouvir e ver além do dito, criando novos dispositivos para análise, ou nos mantemos numa posição de reconhecer os limites do método psicanalítico e que este será sempre o seu alcance. Se considerarmos estas contribuições mais recentes, podemos pensar que estamos mais próximos da primeira alternativa, ou seja, a de pensarmos numa clínica que possa avançar para além do campo da representação - uma clínica do real, para empregar um termo lacaniano.

\section{Bibliografia}

AndRÉ, Serge. A impostura perversa. Trad. Vera Ribeiro e revisão técnica de Manoel Barros da Motta. Rio de Janeiro, Jorge Zahar, 1995.

Birman, Joel. "Le corps et l'affect en psychanalyse". Conferência proferida no Cercle Freudien, em Paris, em 08 de novembro de 1995, inédito.

Clavreul, Jean et al. "O casal perverso", in $O$ desejo e a perversão. Trad. Marina Appenseller. Campinas, Papirus, 1990.

Freud, Sigmund (1923). "O ego e o id", in E.S.B., vol. XIX. Trad. Jayme Salomão. Rio de Janeiro, Imago, 1985.

(1924). "Neurose e psicose", in E.S.B., op. cit.

(1924). "A perda da realidade na neurose e na psicose", in E.S.B., op. cit.

(1925). “A negação", in E.S.B., op. cit.

Hanns, Luiz Alberto. Dicionário comentado do alemão de Freud. Série Analytica. Rio de Janeiro, Imago, 1996.

Helsinger, Luis Alberto. O tempo do gozo e a gozação. A temporalidade na perversão. Rio de Janeiro, Revan, 1996.

Kaufmann, Pierre. Dicionário enciclopédico de psicanálise. O legado de Freud e Lacan. Trad.de Vera Ribeiro e Maria Luiza X. de A. Borges. Rio de Janeiro, Revan, 1996.

Lacan, Jacques. O Seminário. Livro 4 - A relação de objeto. Trad. Dulce Duque Estrada. Rio de Janeiro, Jorge Zahar, 1995.

Miller, Jacques-Alain. Lacan elucidado. Palestras no Brasil/Jacques-Alain Miller. Rio de Janeiro, Jorge Zahar, 1997.

Rey-Flaud, Henri. Comment Freud inventa le fétichisme... et réinventa la psychanalyse. Paris, Payot, 1994. 


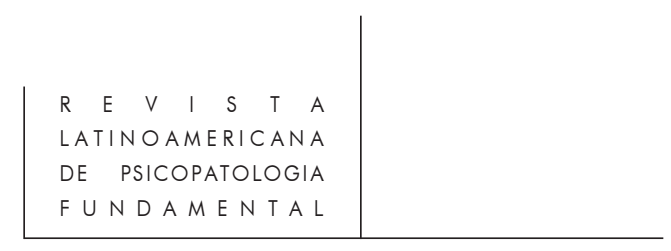

SADE, Donatien A. F. (1795). A filosofia na alcova. Apresentação, revisão e tradução de Eliane Robert Moraes. Salvador, Ágalma, 1995.

SCHNeIDer, Monique. Afeto e linguagem nos primeiros escritos de Freud. Trad. Mônica M. Seincman. São Paulo, Escuta, 1993.

\section{Resumos}

Este artículo principia haciendo algunas reflexiones sobre el sentido de cuerpo para la psicoanalisis, partindo del principio de que él es distinto do de la Biologia. Plantea como foco de la discussión el hombre como ser de lenguaje e analiza la forma de inscripción de las experiencias en el aparato psíquico. Ubica la problemática del perverso en la imagen que él guarda de la castración del cuerpo del Outro. Por fin presenta las contribuciones aportadas por Rey-Flaud cuanto a los niveles de perversión, de acuerdo com la manera de lidar com el objeto.

Dans cet article nous developpons dans um premier moment, quelques refléxions sur le sens qu'a le corps pour la psychanalyse. Nous partons de l'idée que ce sens est distinct de celui conçu par la Biologie. La discussion est centrée sur l'homme en tant qu'un être de language. Nous analisons comment les expériences s'inscrivent dans l'appareil psychique. La problematique du pervers est posée autour de l'image qu'il retient de la castration du corps de l'Autre. Pour finir, nous présentons les contributions apportées par Rey-Flaud quant aux niveaux de perversion. Pour cet auteur ces niveaux sont en rapport avec la manière dont le pervers utilise l'objet.

The first part of this paper is concerned with the treatment given to the body in psychoanalysis assuming that a distinct point of view from that of Biology is taken. It brings into focus man as a language carrier and investigates the forms of inscription of experiences in psychic apparatus. It relates the aspect of the perversion to the image man keeps form outer body castration. Finally, it brings the contributions form Rey-Flaud as to levels of perversion as according to the manner the perverse individual deals with the object. 